\title{
Status of Household Solid Waste Management and Associated Factors in a Slum Community in Kampala, Uganda
}

\author{
Charles Ssemugabo ${ }^{(D)}$, Solomon Tsebeni Wafula $(D)$, Grace Biyinzika Lubega, \\ Rawlance Ndejjo $\mathbb{D}$, Jimmy Osuret, Abdullah Ali Halage, and David Musoke \\ Department of Disease Control and Environmental Health, School of Public Health, \\ Makerere University College of Health Sciences, Kampala, Uganda
}

Correspondence should be addressed to Charles Ssemugabo; cssemugabo@gmail.com

Received 16 September 2019; Revised 6 April 2020; Accepted 22 April 2020; Published 6 May 2020

Academic Editor: Stefano Capolongo

Copyright (c) 2020 Charles Ssemugabo et al. This is an open access article distributed under the Creative Commons Attribution License, which permits unrestricted use, distribution, and reproduction in any medium, provided the original work is properly cited.

Background. Only a third of the total waste generated in slum communities in Kampala is collected and disposed of to the landfill every month. This study assessed the status of household solid waste management and associated factors in a slum community in Kampala, Uganda. Methods. We conducted a community-based cross-sectional study involving 395 households using a semistructured questionnaire and an observational checklist. Proper solid waste management was determined based on possession of waste collection and storage receptacle; collection receptacle ability to minimise nuisances (covered); segregation of waste; presence of flies and other vectors; and collection receptacle fill status. Prevalence rate ratios and their 95\% confidence intervals were used as a measure of association. Results. Only, 41.3\% (163/395) of the households exhibited proper waste management practices. The majority of the households $85.8 \%$ (339/395) owned solid waste storage receptacles, most of which were sacs $61.7 \%$ (209/339) and would minimise nuisances $72.9 \%$ (245/339). The main type of waste collected was biodegradable materials $56.7 \%$ (224/395). The majority of the households $78.7 \%$ (311/395) did not segregate their waste. Solid waste was mainly transported to the collection point by pulling the collecting sac $54.4 \%(215 / 395)$. The city authority $73.9 \%(292 / 395)$ and private companies $12.9 \%$ $(51 / 395)$ were the major entities collecting waste. Factors associated with proper waste management were collecting waste in plastic containers (adjusted PR $=1.27,95 \%$ CI (1.04-1.55)), polythene bags (adjusted PR $=0.26,95 \%$ CI (0.14-0.47)), and paper bags or metallic bins (adjusted PR $=0.13,95 \%$ CI $(0.03-0.44)$ ) as well as awareness of solid waste management laws (adjusted $\mathrm{PR}=1.49,95 \%$ CI (1.20-1.85)) and the dangers of improper solid waste management (adjusted PR $=2.15,95 \%$ CI $(1.51-3.06)$ ). Conclusion. Solid waste management was generally poor. As such, a cascade of interventions that address knowledge, physical, and behavioural aspects of solid waste management is required to improve its management in slum communities.

\section{Introduction}

Eight people died in low-lying slum communities in the outskirts of Kampala due to flash floods during the first rainy season of 2019 [1]. The flash floods were attributed to among others blockage of drainage channels with solid wastes. Many of the households in slum communities have been reported to indiscriminately manage their waste. The problem is likely to escalate with the estimated increase in population and consequently unplanned urbanization resulting in slum development in sub-Saharan Africa.
The generation of solid waste is indeed on the rise globally. Currently, cities around the world generate over 1.3 billion tonnes of waste annually, with this approximated to increase to 2.2 billion tonnes by 2025 [2]. This increase in the amount of solid waste generated is estimated to be much higher in developing countries due to rapid urbanization [3]. Today, Uganda is rapidly growing with annual urbanization and population growth rates of $5.1 \%$ and $3.3 \%$, respectively [4]. However, the existing infrastructure for services such as solid waste management does not cope with the increased urbanization and waste generation [5]. Overall, 
approximately 28,000 tonnes of waste is collected in Kampala and delivered to the landfill every month, which accounts for only $40 \%$ of the total waste generated in the city [6]. The remainder of the waste generated is indiscriminately disposed of resulting in environmental and public health problems such as blockage of drainage channels and consequently flush floods. Other environmental health challenges due to poor solid waste management include pollution (water and soil) resulting in spread of diarrheal diseases [3].

Out of the $1,619,900$ people that live in Kampala [4], approximately $53.6 \%(868,266)$ live in crowded and informal slum settlements, most of which are located in low-lying zones and wetlands (United Nations, 2014). This has resulted in overcrowding and development of more informal settlements. Although solid waste collection is a core service that should function well at community level, it has turned out to be a major challenge that slum residents, city authorities, and leaders are all grappling with [7]. Solid waste management involves control of waste generation, storage, collection, transfer and transport, processing and disposal of solid waste basing on best practices of public health, economics, and environmental consideration [8]. Lubaga division where Kasubi parish is located collects over 3,400 tonnes of solid waste per month [6]. However, a significant percentage of solid waste is dumped in unauthorized sites including drainage channels [6]. Moreover, there are only a few designated communal garbage collection points [7]. This is compounded by the fact that land lords are unwilling to give away a portion of their land for allocation to solid waste collection points, citing poor maintenance of waste collection sites [7, 9].

Kampala Capital City Authority (KCCA) is supporting collection of garbage generated at household level at a subsided fee. However, slum dwellers forfeit this service because of unaffordability, inaccessibility to the waste collection vehicles, disappointments from the solid waste collection companies, and ignorance of importance solid waste management services [10]. Previous studies have not employed observations to ascertain the actual status of solid waste management $[10,11]$, which this study employed. As such, the findings on solid waste management in this study are directly observed. This study therefore aimed at determining status of solid waste management and associated factors in households in a slum community in Kampala, Uganda.

\section{Methods}

2.1. Study Design. We carried out a community-based crosssectional study using a semistructured questionnaire administered and an observational checklist collected data on solid waste management practices among slum households.

2.2. Study Area. The study was carried out in Kasubi Parish in Rubaga Division, Kampala. Kasubi comprises one of the largest slums located in the outskirts of Kampala. Kasubi Parish is comprised of largely informal and substandard housing and small scale businesses. It has a population of 384,386 people living in over nine zones [12]. Kasubi Parish has a high population density, uneven terrain, and poor sanitation and hygiene conditions and is in close proximity with the central business Center of Kampala. Thus, it often experiences challenges in managing solid waste especially at household level.

2.3. Sample Size and Sampling. Using the formulae for crosssectional studies [13] and assuming an alpha of 0.05 , power (1-beta) of 0.80 , a sampling error of $5 \%$, a nonresponse rate of $5 \%$, and a statistically conservative prevalence of $50 \%$ for households that do not properly manage their solid waste, a final sample size of 401 households was obtained. The $50 \%$ prevalence of households which did not properly manage their waste was used to obtain an unbiased sample because previous studies carried out in this area were not focused on proper management of waste [14-16]. The sampling strategy that we used has been previously described [17]. Briefly, the sample size was distributed proportionately based on population size across the six selected out of the nine zones that make up Kasubi Parish. The number of households in each zone was obtained from Lubaga Division offices, and sampling proportionate to size was used to obtain the number of target households from each zone. Households, defined by the Uganda Bureau of Statistics (UBOS) as a group of persons who normally live and eat together [12], were selected using systematic random sampling. In each zone, the number of households was divided by the number of households to be selected to create a sampling interval. The first household in a zone was selected randomly, while subsequent households were selected by skipping a number of households equivalent to the sampling interval until the sampled number of households in that zone was achieved. Within the household, the household head or an adult above 18 years in the absence of the household head was interviewed.

2.4. Data Collection. Data were collected using a semistructured questionnaire and observational checklist. We asked respondents on whether they possessed solid waste containers, categories of waste collected, whether they segregated their waste, how they transported it to the collection point, distance to the nearest collection point, and the cost of data collection. Using an observational checklist, we observed the type of waste container households used, alternative containers to facilitate segregation, presence of files and any other vectors, and whether containers were full or not. The questionnaire was developed based on reviewed literature on solid waste management $[6,10,18,19]$. Data collection tools were pretested in Mulago slum within the city which has similar characteristics with the study area. During pretesting, validity and reliability of individual questions in the questionnaire were assessed. Phrasing of some questions and their anticipated responses were revised to ensure generation of true responses. Trained Research Assistants who were Environmental Health students of 
Makerere University collected the data from all selected households.

2.5. Data Management and Analysis. Data were examined and cleaned on a daily basis during data collection and entered in EpiData version 3.02 (EpiData association; Denmark). To determine the status of household solid waste management (Outcome Variable), which was classified as proper or improper solid waste management, a score was generated from five questions which assessed the solid waste management practices at household level. These included (1) possession of solid waste management containers (yes/no); (2) solid waste management container which minimises nuisances (yes/no); solid waste management receptacle which minimises nuisances is a latent variable that was based on manifest variables, possession of solid waste storage receptacle, and type of solid waste storage receptacle used; the variable solid waste management container which minimises nuisances was defined as receptacle that was well covered and does not permit breeding of vectors such as insects and flies; (3) solid waste which was segregated (yes/ no); (4) files and other vectors not seen around containers (yes/no); and (5) waste storage container not overfilled (yes/ no). As described in previous studies, these questions highlight aspects of solid waste collection and storage at household level typical in a slum setting [20, 21]. Each response to the questions that emphasizes appropriate practice was assigned code 1 and the unsatisfactory practiced one was assigned code 0 . In order to generate the cut-off for the outcome variable, we calculated the mean and median of the 3.045 and 3, respectively. The fact that the mean and median were similar demonstrated that our outcome variable is normally distributed. Since our outcome variable is categorical, the cut-off cannot contain a decimal point. Therefore, we decided to choose the nearby whole number above the mean and median which is 4 as out cut-off. Households that had a score of at least 4 out of 5 were classified as having proper practices and households with score of 3 or less were classified as having improper waste management practices. Other key variables to our study including awareness of waste management laws were measured by asking respondents whether they were aware of any laws govern management of solid waste in their area with responses yes and no. Knowledge on dangers of poor solid waste management was measured using two manifest variables (questions), that is, "do you know the dangers associated with poor solid waste management with responses yes and no" and "mention the dangers associated with poor solid waste management, with responses such as attraction of vectors and vermin, smells, unsightliness, accidents, and fire." Any respondent who mentioned yes on knowledge of dangers of poorly managing solid waste but did not know the actual dangers was scored "0" for the latent variable, knowledge on the dangers of poor waste management. Using STATA version 14.0 (Stata Corp, Texas, USA), we analysed the data on proper waste management and associated factors. A generalized linear model of the Poisson family and log link with robust standard errors while applying a forward elimination method was used to generate prevalence rate (PR) ratios for measuring the association between the outcome and independent variables. Prevalence rate (PR) ratios were used since the outcome of interest was highly prevalent that is $>10 \%$, and odds ratios tend to overestimate the risk ratios in such circumstances [22, 23]. Simple models consisting of an outcome and a single independent variable were run to obtain the unadjusted PRs. In the multivariable model, variables which were significant at simple models $(p<0.05)$ were included while adjusting for age and sex. Stepwise backward elimination was applied until only significant variables and those that improved fit of the model were retained. The unadjusted and adjusted PRs and their corresponding 95\% confidence intervals are presented. A $p$-value of less than 0.05 was considered for statistically significant associations.

2.6. Ethical Considerations. Ethical approval for the study was obtained from the Makerere University School of Public Health Higher Degrees, Research and Ethics Committee (101) and registered by the Uganda National Council for Science and Technology registration (HS 867). Participation in the study was voluntary and household heads provided written informed consent.

\section{Results}

3.1. Sociodemographic Characteristics of Participants. A total of 395 respondents participated in the study out of the 401 resulting in a response rate of $98.5 \%$. Majority of the participants were females $75.9 \%$ (300/395), were Christians $77.5 \%$ (306/395), attained postprimary education $71.4 \%$ (282/395), and were aged $18-29$ years 63.5\% (250/395). Most of the participants $45.1 \%(178 / 395)$ were engaged in business (Table 1).

3.2. Solid Waste Management Practices. The majority of the households $85.8 \%$ (339/395) owned solid waste storage receptacles, most of which were sacs $61.7 \%(209 / 339)$ and minimising nuisances $72.9 \%(245 / 339)$ and were not overfilled $72.9 \%$ (247/339). The main types of waste collected were biodegradable materials (food remains and vegetation) $56.7 \%(224 / 395)$ and ashes and dust 29.4\% (116/395). The majority of the households $78.7 \%$ (311/395) did not segregate their waste. Solid waste was mainly transported to the collection point by pulling the collecting sac $54.4 \%$ (215/ $395)$, carrying over the head $26.6 \%$ (105/395), and using wheel barrows $12.4 \%$ (49/395). The city authority $73.9 \%$ $(292 / 395)$ and private companies $12.9 \%(51 / 395)$ were the major entities collecting waste. Only $32.9 \%$ (130/395) of the households paid for solid waste collection at a cost of less than 1 USD 93.1\% (121/130). Most of the respondents were aware of the solid waste management laws 50.6\% (200/395) and dangers of poor solid waste management $69.6 \%$ (275/ 395). Overall, $41.3 \%$ (163/395) of the households exhibited proper waste management practices (Table 2). 
TABLE 1: Sociodemographic characteristics of participants.

\begin{tabular}{lcc}
\hline Characteristics & Frequency $(n=395)$ & $\begin{array}{c}\text { Percentage } \\
(\%)\end{array}$ \\
\hline Sex & 300 & 75.9 \\
Female & 95 & 24.1 \\
Male & $30.0( \pm 10.8)$ & \\
\hline Age in years [mean $( \pm S D)]$ & 250 & 63.5 \\
14-29 & 104 & 26.4 \\
$30-45$ & 40 & 10.1 \\
46 and above & & \\
\hline Education level & 27 & 6.8 \\
None & 86 & 21.8 \\
Primary & 174 & 44.1 \\
Secondary & 108 & 27.3 \\
Tertiary & & \\
\hline Marital status & 84 & 21.3 \\
Single & 256 & 64.8 \\
Married & 55 & 13.9 \\
Widowed/separated/ & & \\
divorced & & 77.5 \\
Religion & 306 & 22.5 \\
Christian & 89 & 45.1 \\
Muslim & & 14.4 \\
Occupation & 57.2 \\
Business & 42 & 10.4 \\
Casual labour & & \\
Formal employment & & \\
Student & & \\
Others & & \\
\hline
\end{tabular}

3.3. Factors Associated with Household Level Solid Waste Management Practices. Sex, age, education level, marital status, religion, and occupation of the household head were not significantly associated with their household's solid waste management status. Households whose main storage container were plastic bags were 1.3 times more likely to exhibit proper solid waste management practices compared to those that used sacks (adjusted $\mathrm{PR}=1.27,95 \% \mathrm{CI}$ (1.04-1.55)). However, households whose main waste storage receptacle were polythene bags (adjusted $\mathrm{PR}=0.26$, 95\% CI (0.14-0.47)) or other receptacles (paper bags and metallic bins) (adjusted PR $=0.13,95 \%$ CI (0.03-0.49)) were $74 \%$ and $87 \%$, respectively, less likely to exhibit proper solid waste management practices than those who used sacks. Household heads who were aware of solid waste management laws (adjusted PR $=1.49,95 \%$ CI $(1.20-1.85)$ ) were 1.5 times more likely to exhibit proper waste management as compared to those who were not aware. Household heads who knew the dangers of poor solid waste management (adjusted PR $=2.15,95 \%$ CI (1.51-3.09)) were 2.2 times more likely to practice proper solid waste management as compared to those who did not know (Table 3).

\section{Discussion}

This study sought to understand the status of household solid waste management and associated factors in a slum community in Kampala, Uganda. Our findings show that biodegradable waste was the major type of waste collected.
Majority of the households possessed solid waste collection receptacles with sacks as the most used storage receptacle. Few households segregated and paid for collection of their solid waste. Less than half of households exhibited proper solid waste management practices. Households that used plastic containers for waste collection and household heads that were aware of the solid waste management laws and the dangers of improper solid waste management were more likely to properly manage their waste. On the contrary, households that used polythene bags, paper bags, or metallic containers were less likely to practice proper waste management practices. This implies that knowledge and solid waste management utilities are very pertinent to proper management of solid waste in less resourced households.

Biodegradable wastes such as food remains and vegetation were the major form of solid waste generated by households. This is understandable as the slum community is largely a residential area, as such biodegradable waste from the kitchen is often generated. Our findings are similar to those of studies carried out in other parts of Uganda $[10,11,24,25]$. However, it is clear from our findings that few households engaged in segregation of biodegradable waste from other types. Our findings are similar to those from studies in Ghana, Ethiopia, and Kenya where a small percentage of households segregated their waste $[18,19,26]$. Projects implemented in slum communities sensitize households on solid waste management especially separation at the point of practice $[27,28]$, but many households may not afford multiple receptacles required to segregate waste [29]. Unlike our research, a related study found that a relatively high number of households were willing to engage in waste segregation [10] and in another, half of the respondents segregated their waste [11]. Solid waste segregation allows further processing and value extraction through recycling and composting [30]. However, in urban areas most residents do not engage in such processing including compositing attributed partly to absence of a garden [11]. It is important that solid waste management initiatives in slums promote separation of waste at household level so as to facilitate proper solid waste management.

Most households in our study used sacks to collect and store their solid waste. Sacks allow for storage of more wastes for a relatively long period of time compared to other household solid waste collection receptacles such as plastic containers and polythene bags. In addition, sacs are also relatively cheap compared to the plastic containers. However, sacs are not a suitable solid waste receptacle storage as they are nonabsorbent, noncombustible, and not watertight as prescribed by the Kampala solid waste ordinance of 2000 [31]. Relatedly, a similar study reported polythene bags, a substandard waste storage receptacle as the main storage receptacle used in two slums in Uganda [10]. This implies that waste collection in slums is conducted using substandard receptacles that could lead to nuisances around households. Therefore, waste management programmes in slums should encourage use of standard containers for waste collection.

Majority of households did not pay for collection of their solid waste. This implies that their waste might not have been 
TABLe 2: Solid waste management practices at household level.

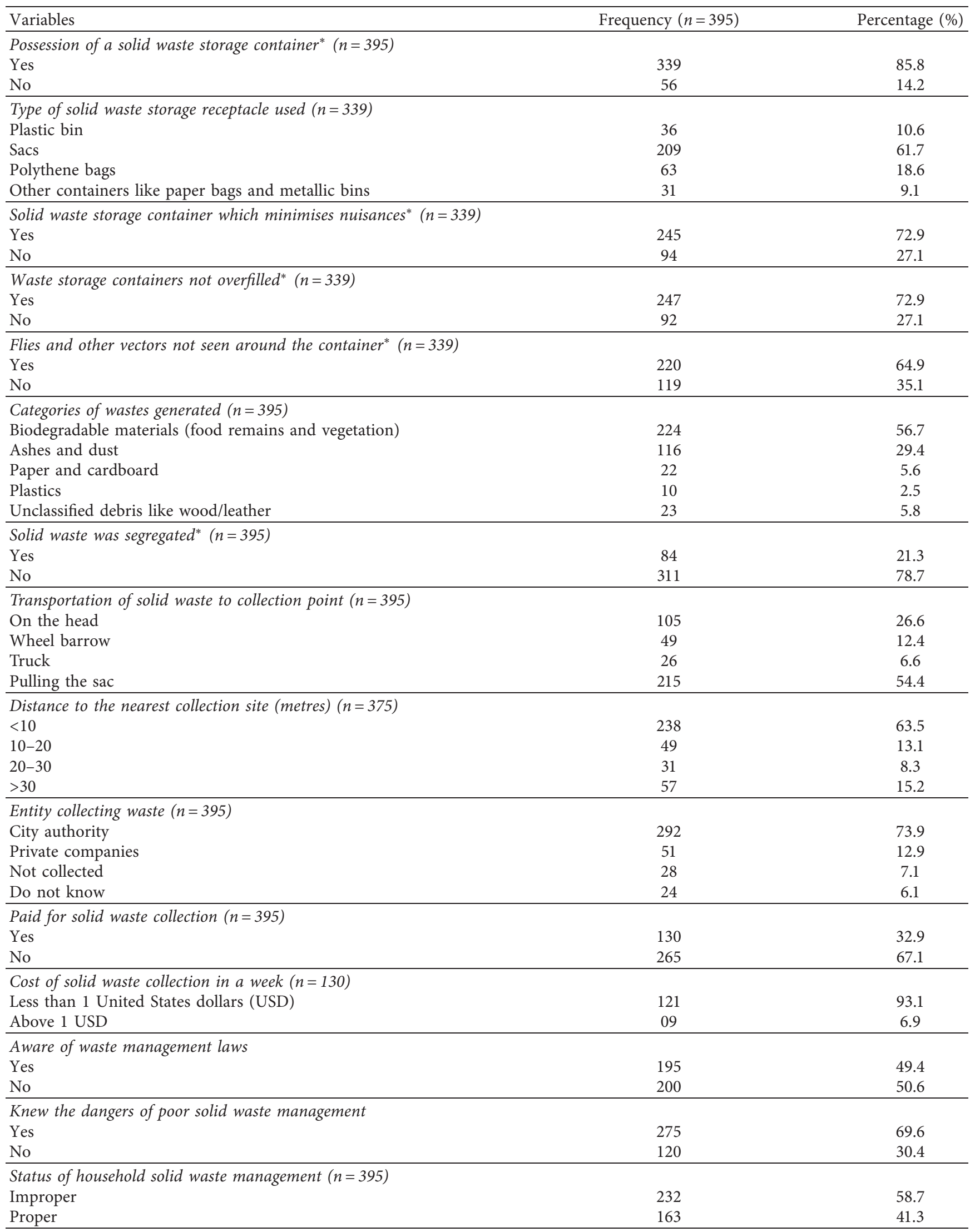

${ }^{*}$ Variables used in calculating scores on the practices on solid waste management at households. 


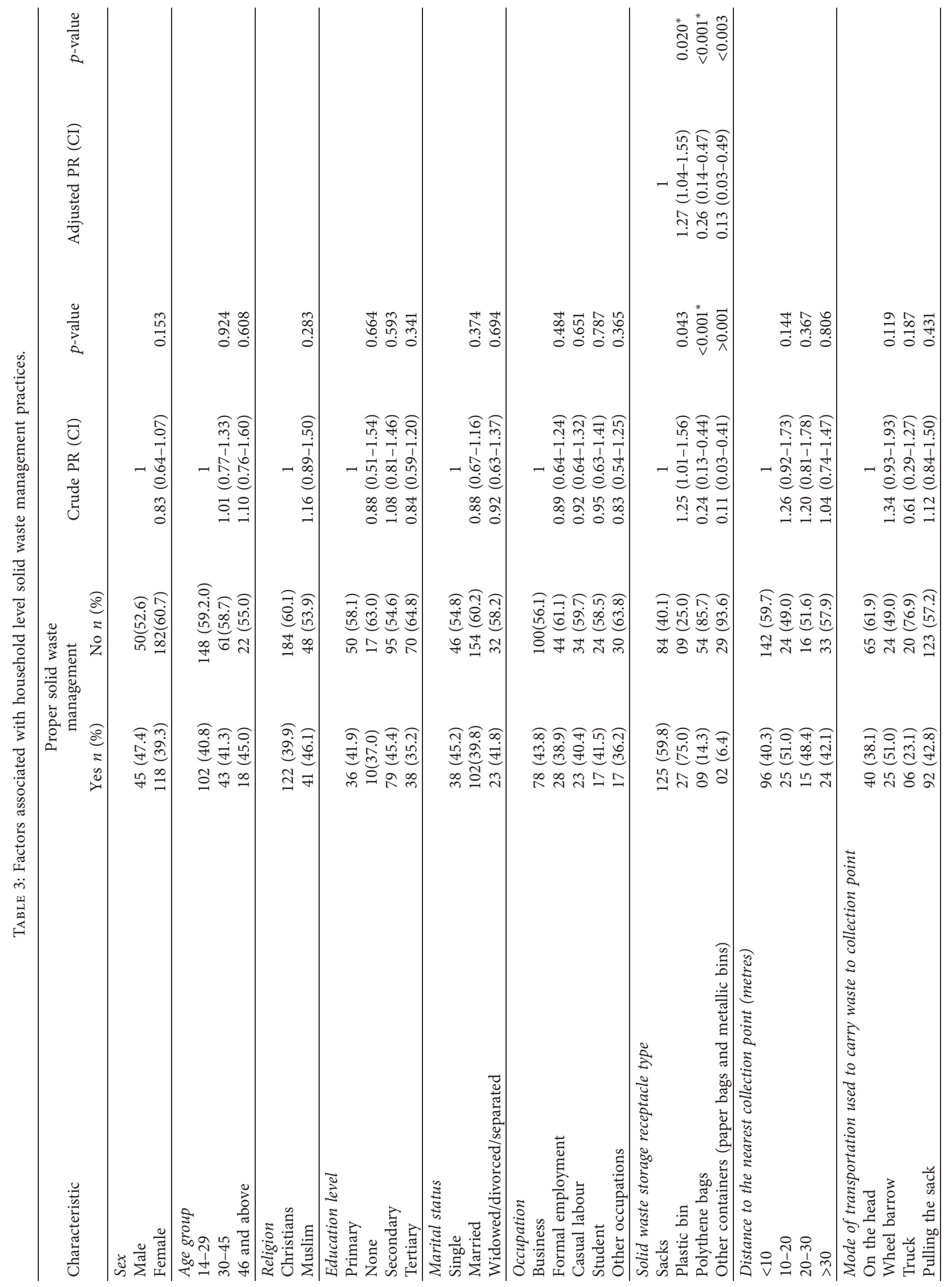




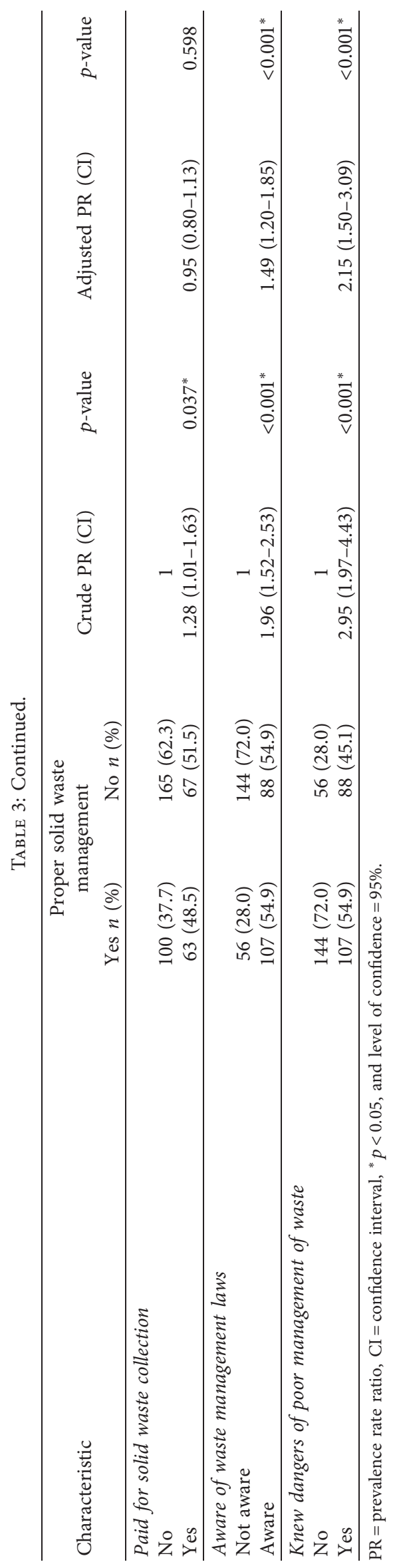


collected by KCCA or other private companies that are involved in waste collection. So, these households were possibly disposing their waste indiscriminately. On the contrary, studies carried out in Nepal, Nigeria, India, and Ethiopia showed that urban households were willing to pay more for proper waste management [32-36]. Indeed, urban residents in Nepal, Nigeria, and Ethiopia where urban residents were paying $0.74,2$, and 1.07 USDs, respectively, for waste collection $[33,34,36]$. Unlike our study, these studies were carried out in more resourced communities. Our study also found that almost all household that paid for waste collection incurred less than 1 United States of American dollar (USD) per collection. Authorities should increase access to solid waste management services and encourage households to utilize them.

Households in our study that used plastic containers were more likely to properly manage their waste compared to those that used sacs. This is understandable as plastic containers usually have tight covering and eliminate nuisances unlike sacs. Covered plastic bins protect the waste from direct exposure to vectors and vermin, as well as mitigate bad odour and unsightedness consequently contributing to proper waste management $[37,38]$. It is also possible that households that could afford plastic containers could also afford to pay waste collection fees furthering proper waste management practices. Indeed, in our study, use of substandard waste collection receptacles is corroborated with improper management of solid waste with households that used polythene and paper bags more likely to improperly manage their waste. Our finding are similar to those from a Ghanaian study which found that indiscriminate dumping of waste was practiced by households that used polythene bags [18]. This demonstrates that waste collection and storage receptacles are very instrumental in ensuring proper waste management and so should be availed at household level within slums.

Among respondents, awareness of dangers of poor waste management and laws that govern management of waste were associated with proper waste management practices. Awareness of the dangers of poor waste management and existing laws and associated penalties increases individual's perceived susceptibility associated diseases and penalties and hence motivates them to adopt appropriate practices [39]. In fact, indiscriminate waste management has been associated with health challenges such as pollution of water and air as well as breeding of vectors among others [40-42]. Our findings are similar to those in studies carried out in Kenya and Guinea that highlighted lack of awareness of proper waste management practices as well as laws and policies as drivers of poor waste management [43, 44]. Conversely, other studies have argued that awareness of legislation or good practices alone does not result into proper solid waste management practices but must be followed with strict enforcement $[45,46]$. So, there is need for solid waste management promotion initiatives to boost slum dwellers' knowledge on associated health risks and penalties in order to facilitate proper solid waste management.

Although some practices were self-reported, status of solid waste management was assessed through observation of waste management receptacles and practices. Given the similarities in slums settings in Kampala, our findings could be generalized to the entire slum community within Kampala. In addition, the study makes a significant contribution to the understanding of waste management practices in slums which have not be well studied especially the use of observations. Although face validity and reliability of the questionnaire were carried out during pretesting, it was not done for individual questions.

\section{Conclusion}

Proper solid waste management was generally low with majority of households using sacks as their waste storage receptacles and not segregating their waste. Use of plastic containers, awareness of waste management laws, and danger of poor waste management were associated with exhibition of proper management practices, while use of substandard receptacles like polythene and paper bags was associated with improper waste management practices. Therefore, in order to improve the solid waste management in slum household, there is need to employ a cascade of interventions that address the knowledge, physical, and behavioural aspects of solid waste management.

\section{Data Availability}

The dataset used during the study is available from the corresponding author upon reasonable request.

\section{Disclosure}

The content of this paper is solely the responsibility of the authors and does not necessarily represent the official views of Stanbic Bank Uganda Limited.

\section{Conflicts of Interest}

The authors declare that they have no conflicts of interest.

\section{Authors' Contributions}

CS, DM, JO, and AAH conceptualized the study and were involved in data collection, analysis, and manuscript writing. STW, GBL, and RN were involved in data collection, analysis, and manuscript writing. All authors read and approved the final manuscript.

\section{Acknowledgments}

The authors would like to thank the Stanbic Bank Uganda Limited for supporting this study. The appreciation goes to the Environmental Health Science students of Makerere University who collected the data for their time and commitment during the course of the research. Special thanks go to the community health workers and local leaders for their support offered during data collection. This study was supported by Stanbic Bank, Uganda Limited. 


\section{References}

[1] ReliefWeb, Eight Dead, Hundreds Displaced as Flash Floods Hit Kampala, ReliefWeb, New York, NY, USA, 2019, https:// reliefweb.int/report/uganda/eight-dead-hundreds-displacedflash-floods-hit-kampala.

[2] D. Hoornweg and P. Bhada-Tata, What a Waste: A Global Review of Solid Waste Management, Vol. 15, Open Access, London, UK, 2012.

[3] R. E. Marshall and K. Farahbakhsh, "Systems approaches to integrated solid waste management in developing countries," Waste Management, vol. 33, no. 4, pp. 988-1003, 2013.

[4] UBOS, Uganda Bureau of Statistics Statistical Abstract 2018, Uganda Bureau of Statistics, Kampala, Uganda, 2018.

[5] MoWE, The 2010 Joint Government of Uganda-Development Partners Sector Review Report, Water and environment sector, Kampala, Uganda, 2010.

[6] A. J. Komakech, N. E. Banadda, J. R. Kinobe et al., "Characterization of municipal waste in Kampala, Uganda," Journal of the Air and Waste Management Association, vol. 64, no. 3, pp. 340-348, 2014.

[7] WaterAid, Solid Waste Management Study Report, WaterAid, London, UK, 2011.

[8] A. Omran, "Investigating households attitude towards recycling of solid waste in Malaysia: a case study," International Journal of Environmental Research, vol. 3, no. 2, pp. 275-288, 2009.

[9] MLHUD, Rubaga Municipality-Slum Settlement Profile, Ministry of Lands, Housing and Urban Development, Ministry of Lands, Housing and Urban Development, Kampala, Uganda, 2016.

[10] T. Mukama, R. Ndejjo, D. Musoke et al., "Practices, concerns, and willingness to participate in solid waste management in two urban slums in central Uganda," Journal of Environmental and Public Health, vol. 2016, Article ID 6830163, 7 pages, 2016.

[11] P. Nsimbe, H. Mendoza, S. T. Wafula, and R. Ndejjo, "Factors associated with composting of solid waste at household level in masaka municipality, Central Uganda," Journal of Environmental and Public Health, vol. 2018, Article ID 1284234, 7 pages, 2018.

[12] UBOS, National Population and Housing Census 2014, Uganda Bureau of Statistics, Kampala, Uganda, 2014.

[13] H. Wiegand and L. Kish, Survey Sampling, Vol. 10, John Wiley and Sons, Inc.,, ýHoboken, NJ, USA, 1968.

[14] W. W. Daniel and C. L. Cross, Biostatistics: A Foundation for Analysis in the Health Sciences, New York, John Wiley and Sons, Inc., Hoboken, NJ, USA, 10th edition, 1999.

[15] S. K. Lwanga and S. Lemeshow, Sample Size Determination in Health Studies: A Practical Manual, World Health Organisation, Geneva, Switzerland, 1991.

[16] S. B. Macfarlane, "Conducting a descriptive survey: 2. Choosing a sampling strategy," Tropical Doctor, vol. 27, no. 1, pp. 14-21, 1997.

[17] C. Ssemugabo, "Knowledge and practices of households on safe water chain maintenance in a slum community in Kampala City, Uganda," Environmental Health and Preventive Medicine, vol. 24, no. 1, p. 45, 2019.

[18] R. M. Yoada, D. Chirawurah, and P. B. Adongo, "Domestic waste disposal practice and perceptions of private sector waste management in urban Accra," BMC Public Health, vol. 14, p. $697,2014$.

[19] S. J. Mukui, "Factors influencing household solid waste management in urban Nyeri Municipality," Ethiopian Journal of Environmental Studies and Management, vol. 6, no. 3, pp. 280-285, 2013.

[20] D. S. Alemayehu, "Household solid waste management practice associated factors and service delivery performance of private solid waste collectors in dire dawa city, eastern Ethiopia," International Journal of Innovative Research in Science, Engineering and Technology, vol. 6, no. 10, 2017.

[21] K. Tassie Wegedie, "Households solid waste generation and management behavior in case of bahir dar city, amhara national regional state, Ethiopia," Cogent Environmental Science, vol. 4, no. 1, Article ID 1471025, 2018.

[22] H. T. O. Davies, I. K. Crombie, and M. Tavakoli, "When can odds ratios mislead?” BMJ, vol. 316, no. 7136, pp. 989-991, 1998.

[23] B. Montreuil, Y. Bendavid, and J. Brophy, "What is so odd about odds?" Canadian Journal of Surgery, vol. 48, no. 5, pp. 400-408, 2005.

[24] J. B. Nyakaana, "Solid waste management in urban centers: the case of Kampala City-Uganda," East African Geographical Review, vol. 19, no. 1, pp. 33-43, 1997.

[25] D. Christensen, D. Drysdale, K. Hansen, J. Vanhille, and A. Wolf, "Partnerships for development: municipal solid waste management in Kasese, Uganda," Waste Management \& Research, vol. 32, no. 11, pp. 1063-1072, 2014.

[26] M. M. Catherine, Assesment of Household Solid Waste Management in Makina Informal Settlements, Kenyatta University Kenya, Nairobi Kenya, 2011.

[27] D. Musoke, "Drinking water supply, sanitation, and hygiene promotion interventions in two slum communities in Central Uganda," Journal of Environmental Public Health, vol. 2018, Article ID 3710120, 9 pages, 2018.

[28] S. M. Elgizawy, S. M. El-Haggar, and K. Nassar, "Slum development using zero waste concepts: construction waste case study," Procedia Engineering, vol. 145, pp. 1306-1313, 2016.

[29] C. Ssemugabo, "A socio-ecological perspective of the facilitators and barriers to uptake of water, sanitation and hygiene interventions in a Slum setting in Kampala, Uganda: a qualitative study," Journal of Water, Sanitation and Hygiene for Development, vol. 124, 2019.

[30] S. Kumar, S. R. Smith, G. Fowler et al., "Challenges and opportunities associated with waste management in India," Royal Society Open Science, vol. 4, no. 3, p. 160764, 2017.

[31] KCCA, The Local Governments (Kampala City Council) (Solid Waste Managment) Ordinace Statutory Instrument, Kampala Capital City Authority, Kampala, Uganda, 2000, https://www. kcca.go.ug/uploads/acts/Solid-waste-ordinance.pdf.

[32] R. K. Rai, M. Nepal, M. S. Khadayat, and B. Bhardwaj, "Improving municipal solid waste collection services in developing countries: a case of bharatpur metropolitan city, Nepal," Sustainability, vol. 11, no. 11, p. 3010, 2019.

[33] B. Maskey and M. Singh, "Households' willingness to pay for improved waste collection service in gorkha municipality of Nepal," Environments, vol. 4, no. 4, p. 77, 2017.

[34] E. E. Ezebilo, "Willingness to pay for improved residential waste management in a developing country," International Journal of Environmental Science and Technology, vol. 10, no. 3, pp. 413-422, 2013.

[35] A. T. Roy and U. Deb, "Households willingness to pay for improved waste management in silchar municipal area: a case study in Cachar district, Assam," Population, vol. 1991, p. 2001, 1951.

[36] S. Mulat, W. Worku, and A. Minyihun, "Willingness to pay for improved solid waste management and associated factors 
among households in Injibara town, Northwest Ethiopia," BMC Research Notes, vol. 12, no. 1, p. 401, 2019.

[37] M. B. M. Yusof, "The role of socio-economic and cultural factors in municipal solid waste generation: a case study in Taman Berling, Johor Bahru," Jurnal Teknologi, vol. 37, pp. 55-64, 2002.

[38] K. K. Azeez, Waste Management Practices in Small Scale Mining Communities in the Wassa West District of West Region, Ghana, School of Public Health, University of Ghana, Accra, Ghana, 2006.

[39] C. L. Jones, J. D. Jensen, C. L. Scherr, N. R. Brown, K. Christy, and J. Weaver, "The Health Belief Model as an explanatory framework in communication research: exploring parallel, serial, and moderated mediation," Health Communication, vol. 30, no. 6, pp. 566-576, 2015.

[40] A. G. Onibokun and A. J Kumuyi, Governance and Waste Management in Africa. Managing the Monster, IDRC, Ottawa, Canada, 1999.

[41] W. Abeyewickreme, A. R. Wickremasinghe, K. Karunatilake, J. Sommerfeld, and K. Axel, "Community mobilization and household level waste management for dengue vector control in Gampaha district of Sri Lanka; an intervention study," Pathogens and Global Health, vol. 106, no. 8, pp. 479-487, 2012.

[42] D. E. Makule, "Pollution of water sources due to poor waste management-the case of Dar-es-Salaam," Schriftenr Ver Wasser Boden Lufthyg, vol. 105, pp. 117-121, 2000.

[43] P. Mugambi and N. Gichuki, "Factors influencing house hold functional solid waste management in Meru town, Meru County, Kenya," International Academic Journal of Information Sciences and Project Management, vol. 2, no. 1, pp. 141-160, 2017.

[44] K. Mamady, "Factors influencing attitude, safety behavior, and knowledge regarding household waste management in Guinea: a cross-sectional study," Journal of Environmental and Public Health, vol. 2016, Article ID 9305768, 9 pages, 2016.

[45] R. K. Henry, Z. Yongsheng, and D. Jun, "Municipal solid waste management challenges in developing countries Kenyan case study," Waste Management, vol. 26, no. 1, pp. 92-100, 2006.

[46] I. A. Al-Khatib, S. Kontogianni, H. Abu Nabaa, N. M. Alshami, and M. I. Al-Sari', "Public perception of hazardousness caused by current trends of municipal solid waste management," Waste Management, vol. 36, pp. 323$330,2015$. 